\title{
Rodrigo González: Iconografía de lo matérico
}

\author{
Morayma Sánchez Vega \\ Lic. Arte y Letras
}

\author{
"El arte no decora...explicita al hombre" \\ Marta Traba
}

En esta nueva etapa de su trabajo artístico, Rodrigo González (1965) irrumpe cuestionándonos, enfrentándonos a realidades sincrónicas. Su obra nos causa un efecto de conmoción al tratar temas sensibles y de impacto social en un lenguaje pictórico austero y de gran fuerza expresiva. Sus cómplices y protagonistas son materiales pobres, los cuales reivindica. Se nutre de las tendencias del informalismo español, principalmente de Antoni Tápies y de los campos de color del expresionismo abstracto norteamericano, los que resemantiza al crear un estilo propio, original y honesto.

El uso de materiales no tradicionales fue introducido en Nicaragua por el grupo Praxis -encabezado por su líder Aróstegui- en los años 60. Si bien Práxis como grupo se proclamó bajo un manifiesto ante la dictadura de los Somoza, Rodrigo lo hace de una manera independiente, reflejando en su trabajo artístico un ambiente de corrupción en nuestras estructuras gubernamentales e institucionales frente a la pobreza que crece día a día. Unifica como un todo expresivo el material empleado y el contenido temático de su obra para reflejar el deterioro de los valores sociales en nuestro país.

En su trayectoria artística, Rodrigo ha mostrado un interés por la búsqueda de soluciones plásticas que cada vez más se han inclinado hacia la abstracción, y a sus experimentaciones ligadas con las texturas ha sumado un nuevo recurso plástico que se ha adecuado a sus propósitos expresivos. El bramante o yute lo incorporó a partir del 2000. Lo introdujo en un primer momento porque le era propicio para expresar la problemática de sequía y hambruna que estaba enfrentando la zona cafetalera de nuestro

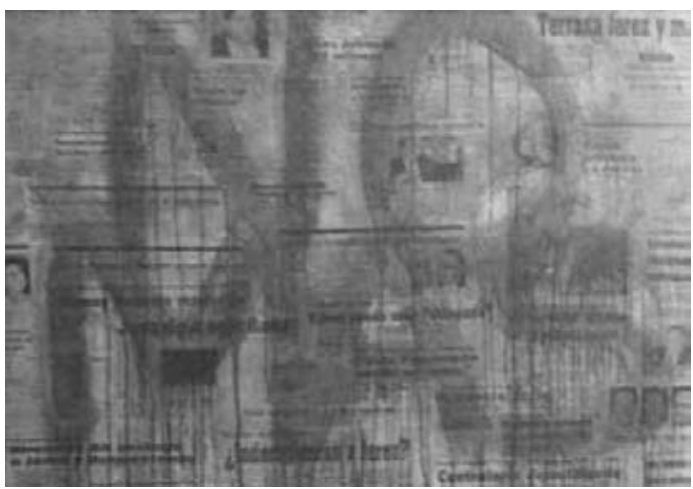
país, versus la vergüenza de los hermanos Centeno, los checazos, la manipulación electoral...

Lo fue empleando como soporte técnico del cuadro que, al dejarse entrever, se convirtió al mismo tiempo en parte activa, y en un elemento más a decodificar en su obra. En NO MAS, compenetrado con los acontecimientos socio-políticos e inspirado en su personaje protagónico Byron Jerez, crea una obra que a 
disposición de collage, deja ver los encabezados y recortes de periódicos de actualidad seleccionados por el artísta para mostrar al espectador toda una suerte de re-lectura que nos lleva a lo metalinguístico. A manera de pintas callejeras, en las que emplea el dripping y su propia grafía, se proclama en contra de los hechos de corrupción frente a la pobreza, esta última provocada por la antropofagia de ciertos personajes públicos.

En su proceso de apropiación con el material deja a un lado el caballete y comienza a colocar su tela en la pared, liberandose de las limitaciones del encuadre. El bramante, lo ha venido desarrollando de una manera decidida y atrevida hasta convertirlo en su constante motivo de expresión, con el que busca diversas posibilidades de lenguaje. Sin apartarse de las superficies texturadas, aglutina una serie de materiales tales como arena volcánica y de mar, polvo de mármol, piedrín de pómez, almidón de yuca, entre otros, con los que logra diferentes sensaciones visuales y táctiles de aspereza y rugosidad, no de gruesos empastes, sino lisos y controlados. Muchas de sus texturas y el color empleado se ven ligados a lo telúrico como parte del propio modus vivendi del artista, quien ha estado relacionado desde niño a la tierra y al agua de Xiloá. Configura un estilo propio al integrar a lo matérico los campos de color (color fields) del expresionismo abstracto. En sus obras plásticas, el color deja de tener el carácter contemplativo y lírico de un Rothko (1903-1970), y lo convierte en símbolo manifiesto de su entorno social. En $\boldsymbol{A Z U L} \boldsymbol{Y} \boldsymbol{B L A N C O}$, estableciendo una composición de espacio-color, alude a los símbolos patrios. El artista, interviene el material ya desgastado en un proceso de construcción, al zurcir, y desconstrucción de la materia, al deshilachar. Son recursos que le sirven para enfatizar y agudizar el dolor en que se encuentra su país, una nación historicamente "construida" por acontecimientos de guerras continuas, desastres naturales

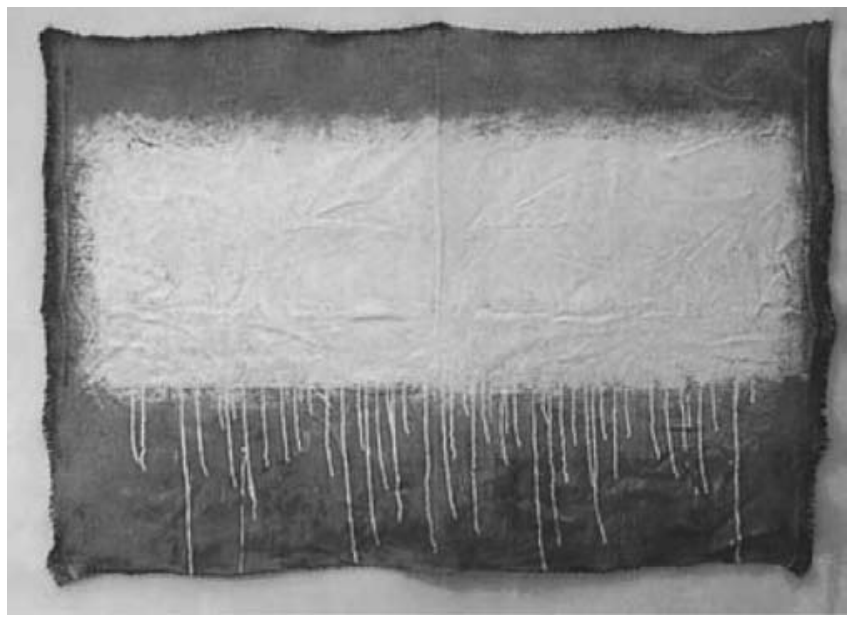
y pobreza, que ha sido y sigue siendo saqueada, desarticulada, $\mathrm{y}$ en donde los valores patrios peligran desintegrarse. Al someter el bramante a estas acciones extrapictóricas, muestra la relación que se establece entre el proceso artístico y el lenguaje expresivo.

En $\boldsymbol{U N A}$ ESPERANZA restringe la gama cromática, y el espacio se encuentra estructurado por medio de franjas que entran en tensión. Un negro que invade y que se 
contrapone al blanco, se convierte en metáfora de angustia, desarraigo, desamparo, dolor, duelo, desesperanza. Mientras en ROJO Y BLANCO el color-símbolo se comporta de una manera lúdica al expresar un rojo representativo de cierto partido político, y que al estar marcado por un blanco de pureza a manera de pinta callejera, alude en un tono irónico a la situación moral en la que se encuentran algunos partidarios. Al mismo tiempo, un rojo y un blanco no dejan de ser referentes también de violencia y paz respectivamente.

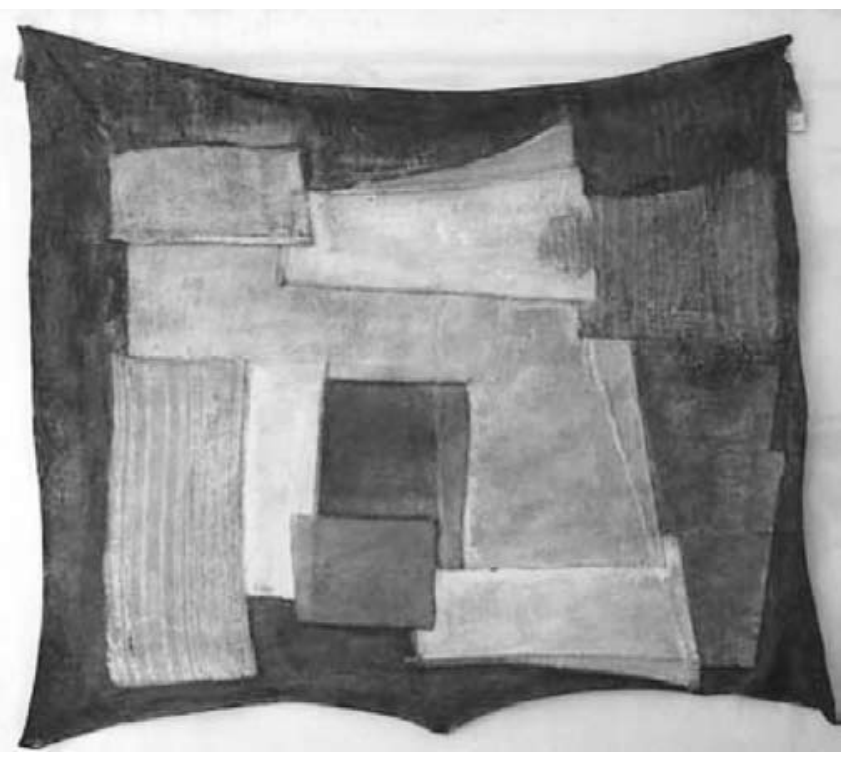

Otras de sus obras tienden a la abstracción geométrica como en $\boldsymbol{L A} \boldsymbol{C I U D A D}$, donde la forma y la relación materialcolor se sintetizan y se vuelven más esenciales, fundamentales. Acumula pedazos de telas que yuxtapone para aludir a la manera espontánea en que se construyen las viviendas de los mas desposeídos, así como la distribución de las ciudades, las que carecen de una concepción arquitectónica, tema que se torna más significativo en un país donde los sismos son una amenaza. Por otro lado, al dejar ver el material tal y como es, establecemos relación con una materia que nos cuestiona la razón de nuestra existencia respecto a lo transitorio de la vida y a la transmutación de la materia.

Nos enfrentamos a una obra plástica de gran valor socio-cultural y artístico porque revitaliza un arte de estética cuestionadora frente a un arte complaciente y alejado de su contexto histórico presente. El arte no puede ser indiferente a los acontecimientos actuales, que se han tornado caóticos y complejos. Rodrigo es sensible a los sucesos sociales que también nos competen a todos, y al ser presentados de una manera artística, se crea otra realidad que hay que resemantizar para desalienarnos. Su obra está marcada por una gran austeridad cromática y de medios, donde la forma y el contenido se vuelven indisolubles y permanecen en constante diálogo, así como su expresión desgarrada se contrapone a una composición controlada, con la que logra equilibrio de fuerzas en su pintura. Rodrigo, desde una perspectiva abstracta, plantea una nueva manera de narrar los acontecimientos históricos de su tiempo. Su obra nos enfrenta no sólo a la pobreza material del hombre sino también a su miseria interior. 